\title{
The effect of mobilization with movement on pain and function in patients with knee osteoarthritis: a randomized double-blind controlled trial
}

Hani A. Alkhawajah ${ }^{1 *}$ (D) and Ali M. Alshami²

\begin{abstract}
Background: Few studies have investigated the effects of mobilization with movement (MWM) in patients with knee osteoarthritis (OA) compared to other procedures. Sham procedures are generally more appropriate control than using no or usual treatments. Moreover, studies investigating the widespread hypoalgesic effects of MWM in patients with knee OA are lacking. The aim was to investigate the effect of MWM on function and pain in patients with knee OA compared to sham MWM.
\end{abstract}

Methods: This is a randomized double-blind (patients and assessor) controlled trial. Forty adult patients with knee OA of grade II and above were recruited to receive either MWM treatment or sham MWM for the knee. The outcome measures included the following: a visual analogue scale (VAS) for pain, the pressure pain threshold (PPT) test, the Western Ontario and McMaster Universities Osteoarthritis (WOMAC) Index, the timed up and go (TUG) test, knee strength and knee range of motion (ROM). The measurements were taken at baseline, immediately after intervention and 2 days later.

Results: Compared with sham MWM, MWM resulted in greater immediate improvement in pain [mean difference $(95 \% \mathrm{Cl}):-2.2(-2.8,-1.6)]$, PPT at both the knee $[176(97,254)]$ and shoulder $[212(136,288)]$, TUG time $[-1.6(-$ $2.1,-1.1)]$, knee flexor strength $[2.0(1.3,2.7)]$ and extensor strength $[5.7(4.1,7.2)]$ and knee flexion ROM [12.8 (9.6, 15.9)] (all, $p<0.001)$ but not knee extension $\operatorname{ROM}[-0.8(-1.6,0.1)](p=0.067)$. After 2 days of intervention, patients who received MWM also demonstrated a greater improvement in pain $[-1.0(-1.8,-0.1)]$, PPT at the shoulder [107 $(40,175)]$, TUG time $[-0.9(-1.4,-0.4)]$, knee flexor strength $[0.9(0.2,1.7)]$ and extensor strength $[2.9(2.1,3.9)]$ and knee flexion ROM $[8.3(4.7,11.9)]$ (all, $p \leq 0.026$ ). However, WOMAC scores and knee extension ROM showed no evidence of change at any stage after intervention ( $p \geq 0.067$ ).

Conclusions: MWM provided superior benefits over sham MWM in terms of local and widespread pain, physical function (walking), knee flexion and extension muscle strength and knee flexion ROM for at least 2 days in patients with knee OA.

Trial registration: ClinicalTrials.gov (NCT02865252), registered on August 12, 2016.

Keywords: Hypoalgesia, Manual therapy, Pressure pain threshold, Quantitative sensory testing

\footnotetext{
* Correspondence: hkhawajah@iau.edu.sa

${ }^{1}$ Department of Physiotherapy, King Fahd Hospital of the University, Imam

Abdulrahman Bin Faisal University, P.O Box 40244, Khobar 31952, Saudi

Arabia

Full list of author information is available at the end of the article
}

(c) The Author(s). 2019 Open Access This article is distributed under the terms of the Creative Commons Attribution 4.0 International License (http://creativecommons.org/licenses/by/4.0/), which permits unrestricted use, distribution, and reproduction in any medium, provided you give appropriate credit to the original author(s) and the source, provide a link to the Creative Commons license, and indicate if changes were made. The Creative Commons Public Domain Dedication waiver (http://creativecommons.org/publicdomain/zero/1.0/) applies to the data made available in this article, unless otherwise stated. 


\section{Background}

Osteoarthritis $(\mathrm{OA})$ is the most prevalent form of joint arthritis [1]. Knee OA accounts for pain and functional disability in $19.2-27.8 \%$ of people aged $>45[2,3]$. Approximately $37 \%$ of people aged $\geq 60$ had knee OA on radiograph [4]. Data on the prevalence of OA in Arabic countries is scarce [5]. However, in Saudi Arabia, a cross-sectional study found that of 300 patients, $53.3 \%$ of men and $60.9 \%$ of women demonstrated radiographic features of knee OA. Eighty per cent of these patients reported knee pain [6].

There is no known cure for OA [7]. The management of knee OA aims to control pain while improving function and quality of life [8]. The most common medical interventions include pharmacological agents and joint replacement surgery. However, the latter is high risk, especially in older patients $[9,10]$. In contrast, other less invasive treatments, such as targeted manual therapy and exercise, are cost-effective and can be safely administered to older patients with OA [7]. Although clinical guidelines report that the efficacy of manual therapy and electrotherapeutic modalities is unclear in patients with knee OA [11], recent high-quality studies [12-14] have found that manual therapy decreases pain, increases range of motion (ROM) and improves physical function.

Mobilization with movement (MWM), which is a type of manual therapy with hypoalgesic effects, increases joint ROM, enhances muscle function and treats specific pathologies [15]. MWM is effective in the management of patients with tennis elbow [16, 17], ankle sprains $[18,19]$, shoulder impingement [20] and hip OA [21]. Other types of manual therapy, namely antero-posterior glide of the tibia on the femur, produce both local and widespread hypoalgesic effects in patients with knee OA [22].

To our knowledge, three studies have attempted to investigate the effects of MWM in patients with knee OA. These studies were either case series [23] or randomized controlled trials (RCTs) [24, 25] that used other treatment procedures in addition to MWM. Sham procedures more clearly distinguish the efficacy of a new procedure beyond the placebo response [26]. In addition, studies that particularly investigate the widespread hypoalgesic effects of MWM in patients with knee OA are lacking. Therefore, the aim of this study is to investigate the immediate and short-term effects of MWM on function and local and distant pain in patients with knee OA compared to sham MWM. This study will serve as the basis for longterm RCTs in the future. The current study is part of a larger study of a master's thesis that has two phases. Phase one is presented in the current study, and phase two aims at evaluating the effect of MWM in a group of patients who demonstrate features of central sensitization.

\section{Materials and methods}

\section{Study design and setting}

This double-blind randomized controlled trial was conducted in the Department of Physiotherapy at King Fahd Hospital of the University (KFHU). The study was retrospectively registered with ClinicalTrials.gov (NCT02865252) and approved by the Institutional Review Board (IRB) (IRB2014-04-323) at Imam Abdulrahman Bin Faisal University. The participants provided their written informed consent to undergo the treatment and to have their data used in the study. The study was carried out with CONSORT reporting guidelines [27] in mind.

\section{Sample size determination and participants}

Sample size calculation was performed using statistical software (G*Power 3.1) with the following combination: analysis of variance, repeated measures, within-between interaction, medium effect size $(\mathrm{f})$ of 0.25 , alpha level of 0.05 , power $(1-\beta)$ of $80 \%$, correlation $(r)$ of 0.5 , with 2 groups and 3 measurements (time points) and nonsphericity correction $(\in)$ of 1 . The estimated desired sample size was 28. A minimum of 18 patients per group was needed taking into consideration a $20 \%$ attrition rate.

Patients with knee OA who attended KFHU were recruited. Patients were diagnosed at the orthopaedic clinic and referred to the Department of Physiotherapy. Patients who were willing to participate in the study were screened for eligibility. The patients were included in the study if they were men or women aged $\geq 40$, had unilateral or bilateral knee OA with a Kellgren and Lawrence (K\&L) grade $\geq 2$ [28], fulfilled the classification criteria of the American College of Rheumatology for knee OA [29], reported peak knee pain of $>3$ on a visual analogue scale (VAS) over the previous $24 \mathrm{~h}$ and were able to walk $\geq 6 \mathrm{~m}$. Patients were excluded if they had knee or lower limb surgery, had received an intraarticular corticosteroid or hyaluronic acid injection within the past 6 months, reported current or past (within 4 weeks) oral corticosteroid use, had inflammatory or neurological disorders, had altered sensation (to cold, heat, or pressure) around their knee, exhibited cognitive difficulties, had low back-related leg pain or had any contraindication to manual therapy.

Blinded to the allocation, participants were recruited consecutively and randomly allocated to either a treatment group (MWM) or a sham group (sham MWM) using a simple randomization procedure. A receptionist who had no other involvement in the study generated the sequential numbers using an online randomization website (https://www.graphpad.com/quickcalcs/randomize1.cfm). Forty numbers were uniquely randomized in equal number to two different groups, and each number and its allocated group was written on a piece of paper and concealed in an opaque envelope. The receptionist informed the treating 
therapist (principal researcher) about patients' allocation after the baseline measurements were taken. Patients were asked to attend on two occasions. The first visit took approximately $2 \mathrm{~h}$, during which measurements were taken at baseline, the intervention was delivered and immediate post-intervention measurements were taken. The second visit occurred 2 days later and lasted 30-45 min for measurement only (short-term effect). The testing procedures were identical for each patient, except that patients in the sham group received sham MWM.

\section{Intervention}

A physiotherapist (principal researcher), blind to the measurements until data analysis, who has 10 years of clinical experience and who is a certified Mulligan practitioner trained in the use of MWM administered treatments to all patients. MWM techniques were performed using a sustained medial, lateral, anterior, posterior or rotation glide of the tibia during active knee flexion and extension. The details of these techniques have been described previously [30]. The glides were tested in all possible directions while the patient was in the supine position using the following order: frontal plane (medial/ lateral), sagittal plane (anterior/posterior) and then rotation. The glide direction that relieved pain to the lowest level and improved knee range most was selected as the glide for treatment. If the movement was not painful, overpressure was added at the end range. The glide direction was examined in weight-bearing if there was no pain in the supine position. If several glide directions showed similar effects in the supine position, these tests were performed in a weight-bearing position to determine the most effective glide direction [23].

In the treatment group, the therapist applied the glide force on the tibia with the knee in mid-range. Then this force was maintained while the patient was flexing and extending the knee to full range. Overpressure was performed at the end range. The MWM treatment technique was repeated 10 times for three sets [23].

In the sham group, the patients were handled similarly to those in the treatment group, but they did not take the glide of direction. Alternatively, the therapist's hands were lightly touching the knee skin without pressure, one hand on the tibia and one on the femur. Active knee flexion and extension movements, however, were performed 10 times for three sets.

\section{Outcome measures}

An independent experienced physiotherapist (assessor) from the Department of Physiotherapy (with $>5$ years of clinical experience) who was blinded to the allocation of the patients collected the demographic data and baseline measurements of all outcome measurements. Then, the assessor left the room to remain blind to conditions while the principal researcher applied either MWM treatment or sham MWM interventions according to the patient's allocated group. After that, the principal researcher left the treatment area and the assessor performed the outcome measurements immediately after the intervention in a similar manner to the baseline measurements. Patients were asked not to discuss their treatment experience with the assessor. Two days later, the assessor performed the outcome measurements again to assess short-term effects [31].

\section{Primary outcomes \\ Visual analogue scale (VAS)}

Current pain intensity was measured using a 10-cm VAS with end points marked 'no pain' and 'worst pain imaginable'. The VAS is a valid and reliable measure of pain intensity [32-35].

\section{Pressure pain threshold (PPT)}

A digital pressure algometer (Somedic AB, Farsta, Sweden) was used to quantify pain intensity in accordance with similar clinical studies [16, 22]. This measure has demonstrated high reliability with an intraclass correlation coefficient [ICC $(2,3)]$ of 0.97 [36]. PPT is the lowest stimulus intensity at which a person feels mechanical pain. Increased values of PPT may indicate hypoalgesia or decreased response to mechanical pain stimuli [37].

The most tender point on the medial aspect of the participant's affected knee was palpated, marked and photographed to ensure standardization between measurements. With the participant in a side-lying position, a $1 \mathrm{~cm}^{2}$ algometer probe was used to apply pressure at $90^{\circ}$ of knee flexion perpendicular to the skin at a rate of $40 \mathrm{kPa} / \mathrm{s}$. Participants were asked to press a button when the sensation of non-painful pressure turned to become painful. The PPT value was recorded at this point. PPT was also examined on the middle deltoid, $10 \mathrm{~cm}$ away from the acromion of the ipsilateral shoulder, to investigate any widespread changes in sensitivity at a distant site. Three measurements were performed in each area (knee and shoulder), and the mean value was recorded for analysis. A rest period of $20 \mathrm{~s}$ was given after each measurement.

\section{Western Ontario and McMaster universities osteoarthritis (WOMAC) index}

This self-administered questionnaire was presented using a five-point ordinal scale with five categorical responses (numerical value of $0-4)$. WOMAC was designed to measure perceived pain, stiffness and dysfunction. High WOMAC scores reflect greater severity across the three measured domains [38]. WOMAC has moderate-to-excellent reliability 
and validity to test pain, stiffness and function, especially in patients with hip or knee OA [38-40].

\section{Timed up and go (TUG)}

This common test used to assess walking ability has been described in detail previously [41]. TUG has showed high inter- and intra-rater reliability [ICC (2, $1)=0.96-0.97$ ] in an arthritic population [42]. One practice trial was performed prior to testing. Three measurements were performed, and the mean value was recorded for analysis. A rest period of $15 \mathrm{~s}$ was given after each measurement.

\section{Secondary outcomes}

\section{Hand-held dynamometer}

A digital dynamometer (Commander Power Track II, JTECH Medical Industries, Midvale, USA) was used to examine muscle strength and force development. It has good-to-excellent intra- and inter-rater reliability [ICC $(2,1) \geq 0.70]$ and moderate-to-excellent validity to test muscle strength [43, 44]. The strength of knee flexors and extensors in kilograms was measured while sitting with the knee at $90^{\circ}$ flexion. To provide resistance throughout the range, the hand-held dynamometer was placed on the distal tibia anteriorly when examining knee extensors and placed on the posterior ankle when examining knee flexors. Three repetitions were performed in each direction, and the mean value was used for analysis. A rest period of $15 \mathrm{~s}$ was given after each repetition.

\section{Standard goniometer}

A standard goniometer (EZ Read Jammar, Sammons Preston, Warrenville, USA) was used to measure active knee flexion and extension ROM in the supine position. The test was performed three times for each direction, and the mean value was used for analysis. Goniometer measurement demonstrated moderate to high inter-rater reliability $(\mathrm{ICCs}=0.59-0.90)$ [45].

\section{Statistical analysis}

Data were analysed using IBM SPSS for Windows (version 24.0). Descriptive analysis included means, standard deviations, medians and interquartile ranges. Q-Q plot and Shapiro-Wilk test of standardized residuals were performed for checking the normality of residuals. All continuous variables were approximately normally distributed, except for knee extension ROM. For this variable, the assumption was not met even after transformation, but the model residuals were acceptable. Homoscedasticity was tested for WOMAC by plotting a scatterplot of the standardized residuals against the predicted values. Linearity assumption was assessed by plotting a scatterplot of outcome values at follow-ups against baseline values in each treatment group. The scatterplots did not indicate major departure from these assumptions. The primary analysis was performed on an intention-totreat basis, and all randomised participants were included. For continuous outcomes, the least square means (LS means) and their 95\% confidence intervals (CIs) were estimated using a linear mixed model (LMM) for repeated measures with participant as a random effect, baseline score as a covariate $[46,47]$ and outcomes at two follow-up visits as a dependent variable. This model contained the treatment group, time, baseline-by-time interaction and group-by-time interaction as fixed-effects with an unstructured covariance matrix among time points. For the WOMAC, which was measured with a single follow-up time ( 2 days), analysis of covariance (ANCOVA) with baseline value as a covariate was used. Mean changes for each group at each time point and mean between-group differences were estimated using appropriate contrasts in the models. All data were regarded as significant at $p<0.05$ (two-sided).

\section{Results}

Forty-four patients were screened for eligibility. Forty patients satisfied the criteria. Of the 40 patients, four were excluded because of tibial osteotomy, two because of altered sensation around their knees and one because they were unable to walk a 6 -m distance with or without an aid. Figure 1 shows the enrolment and randomization process. Table 1 shows the demographic data of the patients. Table 2 demonstrates the direction of glide applied for the MWM intervention. The medial glide of the tibia over the femur was the most common technique.

The group-by-time interaction for the LMM was statistically significant for VAS $(F=27.69, p<0.001)$, PPT at the knee $(F=10.86, p<0.001)$, PPT at the shoulder $(F=16.06, p<0.001)$, TUG $(F=21.31, p<0.001)$, knee flexor strength $(F=15.37, \quad p<0.001)$, knee extensor strength $(F=32.46, p<0.001)$ and knee flexion ROM $(F=36.83, p<0.001)$. This interaction was not statistically significant for knee extension ROM $(F=2.30, p=$ $0.115)$. The results show significantly greater mean changes from baseline for knee flexion ROM in the treatment group compared to the sham group at followup visits 1 and 2 [the mean between-group difference was $12.8(p<0.001)$ and $8.3(p<0.001)$, respectively]. Tables 3 and 4 show the LS mean changes and their 95\% CIs in the outcomes of the treatment and sham groups over time estimated using LMM and ANCOVA analyses. The tables also report the difference in the LS mean change between the groups at follow-up visits 1 and 2 . Compared to those receiving sham MWM, the patients who received MWM demonstrated an immediate greater decrease in pain, a greater increase in PPT at both the knee and shoulder, a greater decrease in TUG time, a greater increase in knee flexor and extensor strength 


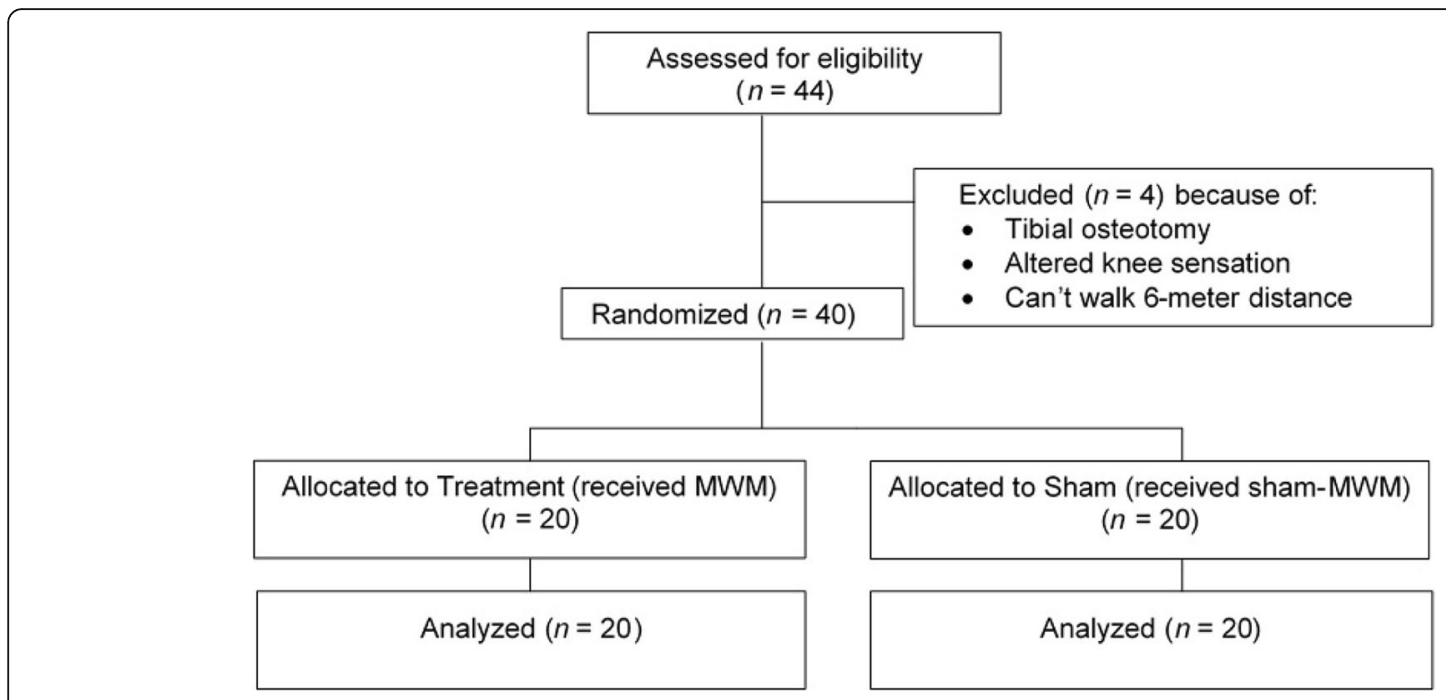

Fig. 1 Consort diagram of patients enrolment and randomization

and a greater increase in knee flexion ROM (all, $p<$ $0.001)$ but not in extension ROM $(p=0.067)$. Two days after intervention, patients who received MWM demonstrated a greater decrease in pain, a greater increase in PPT at the shoulder, a greater decrease in TUG time, a greater increase in knee flexor and extensor strength and a greater increase in knee flexion ROM compared to those who received sham MWM (all, $p \leq 0.026$ ). However, no significant differences were found between the treatment and sham groups in PPT at the knee ( $p=$ $0.142)$ or knee extension ROM ( $p=0.499)$ (Table 3$)$. The ANCOVA revealed no significant differences between the two groups in the total score or any sub-scale of WOMAC $(p \geq 0.392)$ (Table 4).

\section{Discussion}

This study investigated the immediate and short-term effects of MWM compared to sham MWM on function and local and widespread pain in patients with knee OA. MWM resulted in an immediate reduction in pain as

Table 1 Characteristics of patients in both groups at baseline

\begin{tabular}{|c|c|c|}
\hline & $\begin{array}{l}\text { MWM }(n=20) \\
\text { Mean } \pm \text { SD }\end{array}$ & $\begin{array}{l}\text { Sham }(n=20) \\
\text { Mean } \pm \text { SD }\end{array}$ \\
\hline Age (years) & $56.5 \pm 7.6$ & $56.6 \pm 8.5$ \\
\hline BMI $\left(\mathrm{kg} / \mathrm{m}^{2}\right)$ & $32.6 \pm 7.8$ & $33.3 \pm 6.1$ \\
\hline Duration of symptoms (months) & $51(46)$ & $48(42)$ \\
\hline VAS $(10 \mathrm{~cm})$ & $6.5 \pm 1.9$ & $5.7 \pm 2.0$ \\
\hline Gender (male/ female) & $13 / 7$ & $12 / 8$ \\
\hline Affected knee side (right/left) & $6 / 14$ & $10 / 10$ \\
\hline K\&L knee OA grade $(2 / 3 / 4)$ & $14 / 4 / 2$ & $13 / 3 / 4$ \\
\hline
\end{tabular}

measured by VAS. The mean difference in VAS scores was $2.7 \mathrm{~cm}$ and $0.9 \mathrm{~cm}$ immediately post-intervention and after 2 days, respectively, more than the 'minimal clinically relevant' difference of $0.84 \mathrm{~cm}$ [48]. This effect was similar to previously recorded results for ankle sprains [49], de Quervain's tenosynovitis [50], lateral epicondylalgia [51] and hip OA [21]. This reduction of pain lasted for 2 days. A similar result was found in patients with knee OA where MWM was applied in a case series [23] or in RCT's where MWM was used in combination with other treatments [24, 25].

A reduction of mechanical pain, as measured by an algometer, was also observed following MWM, as demonstrated by increased PPTs in the knee. This result is similar to the findings of studies of spinal mobilization $[31,52]$ and peripheral joint mobilization of the elbow [53] and knee OA [22]. Interestingly, in this study, an improvement in PPT was seen in the distant area (i.e. shoulder) in the treatment group but not in the sham group. The increase in PPT was $>15 \%$ immediately postintervention (for knee and shoulder) and after 2 days (for the shoulder), which is considered to reflect a clinically significant effect [22]. Previous studies revealed that

Table 2 Direction of glide chosen for the MWM intervention

\begin{tabular}{ll}
\hline Direction of glide & $\begin{array}{c}\text { MWM } \\
(n=20)\end{array}$ \\
\hline Medial glide & 7 \\
Medial + internal rotation glide & 2 \\
Lateral glide & 3 \\
Lateral + external rotation glide & 1 \\
Internal rotation glide & 5 \\
Anterior glide & 2
\end{tabular}

MWM Mobilization with movement 
Table 3 Comparison of pain, pressure pain threshold, timed 'up and go', muscle strength, and range of motion between both groups

\begin{tabular}{|c|c|c|c|c|c|c|c|}
\hline \multirow[b]{2}{*}{ Variables } & \multirow[b]{2}{*}{ Group } & \multicolumn{3}{|c|}{ Immediately after intervention } & \multicolumn{3}{|l|}{ After 2 days } \\
\hline & & $\begin{array}{l}\text { Change from baseline } \\
\text { mean }(95 \% \mathrm{Cl})\end{array}$ & $\begin{array}{l}\text { Difference in mean } \\
\text { change }(95 \% \mathrm{Cl})\end{array}$ & $p$-value & $\begin{array}{l}\text { Change from baseline } \\
\text { mean }(95 \% \mathrm{Cl})\end{array}$ & $\begin{array}{l}\text { Difference in mean } \\
\text { change }(95 \% \mathrm{Cl})\end{array}$ & $p$-value \\
\hline VAS (cm) & $\begin{array}{l}\text { MWM } \\
\text { Sham }\end{array}$ & $\begin{array}{l}-2.7(-3.1,-2.2) \\
-0.5(-0.9,-0.0)\end{array}$ & $-2.2(-2.8,-1.6)$ & $<0.001^{*}$ & $\begin{array}{l}-0.9(-1.5,-0.3) \\
0.1(-0.5,0.7)\end{array}$ & $-1.0(-1.8,-0.1)$ & $0.026^{*}$ \\
\hline PPT knee (kPa) & $\begin{array}{l}\text { MWM } \\
\text { Sham }\end{array}$ & $\begin{array}{l}185(131,240) \\
10(-45,64)\end{array}$ & $176(97,254)$ & $<0.001^{*}$ & $\begin{array}{l}65(29,102) \\
27(-9,63)\end{array}$ & $39(-14,91)$ & 0.142 \\
\hline PPT shoulder (kPa) & $\begin{array}{l}\text { MWM } \\
\text { Sham }\end{array}$ & $\begin{array}{l}209(155,263) \\
-3(-57,51)\end{array}$ & $212(136,288)$ & $<0.001^{*}$ & $\begin{array}{l}106(58,154) \\
-2(-49,46)\end{array}$ & $107(40,175)$ & $0.003^{*}$ \\
\hline TUG (seconds) & $\begin{array}{l}\text { MWM } \\
\text { Sham }\end{array}$ & $\begin{array}{l}-1.6(2.0,-1.2) \\
0.0(-0.4,0.4)\end{array}$ & $-1.6(-2.1,-1.1)$ & $<0.001^{*}$ & $\begin{array}{l}-0.9(-1.3,-0.5) \\
-0.0(-0.4,0.4)\end{array}$ & $-0.9(-1.4,-0.4)$ & $0.001^{*}$ \\
\hline HHD knee flexion (kg) & $\begin{array}{l}\text { MWM } \\
\text { Sham }\end{array}$ & $\begin{array}{l}2.5(2.0,3.0) \\
0.5(-0.1,1.0)\end{array}$ & $2(1.3,2.7)$ & $<0.001^{*}$ & $\begin{array}{l}1.1(0.6,1.6) \\
0.2(-0.4,0.7)\end{array}$ & $0.9(0.2,1.7)$ & $0.018^{*}$ \\
\hline HHD knee extension (kg) & $\begin{array}{l}\text { MWM } \\
\text { Sham }\end{array}$ & $\begin{array}{l}6.0(5.0,7.1) \\
0.4(-0.7,1.5)\end{array}$ & $5.7(4.1,7.2)$ & $<0.001^{*}$ & $\begin{array}{l}3.3(2.7,4.0) \\
0.3(-0.3,1.0)\end{array}$ & $2.9(2.1,3.9)$ & $<0.001^{*}$ \\
\hline ROM knee flexion $\left(^{\circ}\right)$ & $\begin{array}{l}\text { MWM } \\
\text { Sham }\end{array}$ & $\begin{array}{l}15.1(12.9,17.4) \\
2.4(0.2,4.6)\end{array}$ & $12.8(9.6,15.9)$ & $<0.001^{*}$ & $\begin{array}{l}10.2(7.7,12.7) \\
1.9(-0.6,4.4)\end{array}$ & $8.3(4.7,11.9)$ & $<0.001^{*}$ \\
\hline ROM knee extension $\left(^{\circ}\right)$ & $\begin{array}{l}\text { MWM } \\
\text { Sham }\end{array}$ & $\begin{array}{l}-0.6(-1.2,-0.1) \\
0.1(-0.5,0.7)\end{array}$ & $-0.8(-1.6,0.1)$ & 0.067 & $\begin{array}{l}-0.3(-0.9,0.3) \\
-0.0(-0.6,0.5)\end{array}$ & $-0.3(-1.1,0.5)$ & 0.499 \\
\hline
\end{tabular}

CI Confidence interval, HHD Hand-held dynamometer, MWM Mobilization with movement, ROM Range of motion, PPT Pressure pain threshold, TUG Timed "Up and Go", VAS Visual analogue scale

"Significance difference $(p<0.05)$

mobilization of the cervical spine decreases hyperalgesia in the upper limbs $[31,54]$ and that knee mobilization induces hypoalgesic responses down to the heel [22].

Research has shown that joint mobilization not only initiates local physiological mechanisms but also involves central mechanisms such as facilitation of inhibitory pathways in the spinal cord or descending inhibitory pathways from higher levels in the brainstem [22]. Skyba et al. [55] reported that serotonergic and noradrenergic receptors in the spinal cord mediate analgesia produced by knee joint mobilization.

Knee flexion ROM improved significantly immediately after intervention with MWM in this study. This result corresponds to previous studies of the knee and hip. A case series [23] and RCT [24] reported improvement of knee flexion ROM following MWM in patients with knee OA. Beselga et al. [21] reported immediate improvement of hip flexion and internal rotation ROM following a single treatment of MWM in patients with hip OA.

The present study demonstrated an immediate and short-term effect of knee MWM on motor activity, as indicated by significant improvements in knee flexor and extensor muscle strength. These improvements may be due to the reversal of reflex pain inhibition [56]. Alteration in motor activity may also be an indication of a response that is mediated at the level of the central nervous system [56]. MWM improved quadriceps muscle strength significantly in patients with knee OA up to 1year follow-up [24]. Mobilization of the cervical spine improved the function of deep neck flexor in patients with neck pain [52] and increased pain-free grip strength in patients with lateral epicondylalgia [16, 31].

In this study, MWM improved TUG time. The decrease in time needed to walk $6 \mathrm{~m}$ was $1.6 \mathrm{~s}$ immediately

Table 4 Comparison of the Western Ontario and McMaster Universities Osteoarthritis Index between both groups

\begin{tabular}{|c|c|c|c|c|}
\hline Variables & Group & $\begin{array}{l}\text { Change from baseline } \\
\text { mean }(95 \% \mathrm{Cl})\end{array}$ & $\begin{array}{l}\text { Difference in mean } \\
\text { change }(95 \% \mathrm{Cl})\end{array}$ & $p$-value \\
\hline Pain scale & $\begin{array}{l}\text { MWM } \\
\text { Sham }\end{array}$ & $\begin{array}{l}-0.2(-1.1,0.9) \\
-0.1(-0.9,0.7)\end{array}$ & $-0.1(-1.3,1.0)$ & 0.813 \\
\hline Stiffness scale & $\begin{array}{l}\text { MWM } \\
\text { Sham }\end{array}$ & $\begin{array}{l}0.0(-0.4,0.5) \\
-0.1(-0.5,0.3)\end{array}$ & $0.1(-0.5,0.7)$ & 0.700 \\
\hline Function scale & $\begin{array}{l}\text { MWM } \\
\text { Sham }\end{array}$ & $\begin{array}{l}0.3(-1.9,2.4) \\
1.6(-0.6,3.7)\end{array}$ & $-1.3(-4.4,1.8)$ & 0.392 \\
\hline Total score & $\begin{array}{l}\text { MWM } \\
\text { Sham }\end{array}$ & $\begin{array}{l}-0.2(-3.1,2.7) \\
1.6(-1.3,4.4)\end{array}$ & $-1.8(-5.9,2.4)$ & 0.396 \\
\hline
\end{tabular}


after the intervention, which is considered to reflect a clinically significant effect [42]. Our finding is consistent with the study by Altmıs et al. [25]. In patients with hip OA, Beselga et al. [21] found that MWM reduced the time needed to walk $6 \mathrm{~m}$ in this functional test. However, another manual therapy technique, namely anteroposterior glide, had no effect on this test in patients with knee OA [22]. This disagreement may be attributed to the different mobilization techniques used, test procedures and/or the characteristics of the patients in the two studies. These contradictory findings emphasize the need of further research in this area. In this study, several patients received MWM in weight-bearing positions. Thus, patients simultaneously received self-feedback from their painless joint movement.

While the reduction of pain and the improvement of physical function were achieved by MWM, the WOMAC Index scores did not change. This may be because the grade of OA (on the K\&L scale) was relatively low, which may represent a non-major limitation of functional activity. Moreover, 2 days might not be sufficient for a perceived improvement in daily activities. Moss et al. [22] reported no improvement in WOMAC Index scores after the initial effect of antero-posterior glide in patients with knee OA. However, longer sessions of MWM or other manual therapy techniques in combination with exercise produced significant improvements in WOMAC Index scores in other studies $[24,57,58]$.

A strength of this study is that a sham treatment was used, which is considered more appropriate than no or usual treatment as a control. A limitation of is the shortterm design, which may suggest that the immediate changes of any outcome cannot be extrapolated to longterm changes. However, significant improvements in pain, function, ROM and muscle strength were noted in this study, as in previous studies [21-23].

\section{Conclusion}

The current study suggests that MWM but not sham MWM for patients with knee OA provides a local and widespread hypoalgesic effect, increases knee flexion ROM, increases knee flexor and extensor strength and improves physical function. Although this study demonstrated immediate and short-term effects that persisted for 2 days after the intervention, more research is needed to determine the long-term efficacy of this approach.

\footnotetext{
Abbreviations

ANCOVA: Analysis of covariance; Cl: Confidence interval; ES: Effect size; ICCs: Intraclass correlation coefficients; IRB: Institutional review board; K\&L: Kellgren and Lawrence; KFHU: King Fahd Hospital of the University; LMM: Linear mixed model; MWM: Mobilization with movement;

OA: Osteoarthritis; PPT: Pressure pain threshold; RCTs: Randomized controlled trials; ROM: Range of motion; TUG: Timed "Up and Go"; VAS: Visual analogue scale; WOMAC: Western Ontario and McMaster Universities
}

\section{Acknowledgements}

The authors in this study would like to thank physiotherapists Mr. Ahmed Aldandan and Ms. Ranya Alsaif for their help in the process of data collection, and Mr. Melbin John for his assistance with data analysis.

\section{Authors' contributions}

This research was a part of a thesis submitted as partial fulfilment of the requirements for the degree of Master of Science. HA is a former postgraduate student who made data collection and wrote all the sections of this research under close supervision of AA who analyzed and interpreted the patient's data. All authors read and approved the final manuscript.

\section{Funding}

The authors in this study declare that this research did not receive any specific grant from funding agencies in the public, commercial, or not-forprofit sectors.

\section{Availability of data and materials}

The datasets used and/or analyzed during the current study are available from the corresponding authors on reasonable request.

\section{Ethics approval and consent to participate}

The ethical approval was obtained from the Institutional Review Board (IRB) (IRB-2014-04-323) at Imam Abdulrahman Bin Faisal University. The participants provided their written informed consent to undergo the treatment and to have their data used in the study.

\section{Consent for publication}

The participants in this study provided their written informed consent to undergo the treatment and to have their data used in the study.

\section{Competing interests}

The authors declare that they have no competing interests.

\section{Author details}

${ }^{1}$ Department of Physiotherapy, King Fahd Hospital of the University, Imam Abdulrahman Bin Faisal University, P.O Box 40244, Khobar 31952, Saudi Arabia. ${ }^{2}$ Department of Physical Therapy, College of Applied Medical Sciences, Imam Abdulrahman Bin Faisal University, P.O. Box 2435, Dammam 31441, Saudi Arabia.

Received: 19 October 2018 Accepted: 20 September 2019

Received: 19 October 2018 Accepted: 20 S

\section{References}

1. Creamer P, Hochberg MC. Osteoarthritis Lancet. 1997;350(9076):503-8.

2. Felson DT, Naimark A, Anderson J, Kazis L, Castelli W, Meenan RF. The prevalence of knee osteoarthritis in the elderly. The Framingham Osteoarthritis Study. Arthritis Rheum. 1987;30(8):914-8.

3. Jordan JM, Helmick CG, Renner JB, Luta G, Dragomir AD, Woodard J, Fang F, Schwartz TA, Abbate LM, Callahan LF, et al. Prevalence of knee symptoms and radiographic and symptomatic knee osteoarthritis in African Americans and Caucasians: the Johnston County osteoarthritis project. J Rheumatol. 2007:34(1):172-80.

4. Lawrence RC, Felson DT, Helmick CG, Arnold LM, Choi H, Deyo RA, Gabriel S, Hirsch R, Hochberg MC, Hunder GG, et al. Estimates of the prevalence of arthritis and other rheumatic conditions in the United States. Part II Arthritis Rheum. 2008:58(1):26-35.

5. Alghamdi MA, Olney S, Costigan P. Exercise treatment for osteoarthritis disability. Ann Saudi Med. 2004;24(5):326-31.

6. Al-Arfaj A, Al-Boukai AA. Prevalence of radiographic knee osteoarthritis in Saudi Arabia. Clin Rheumatol. 2002;21(2):142-5.

7. Gross KD, Hillstrom $\mathrm{H}$. Knee osteoarthritis: primary care using noninvasive devices and biomechanical principles. Med Clin North Am. 2009;93(1):179-200.

8. Mease PJ, Hanna S, Frakes EP, Altman RD. Pain mechanisms in osteoarthritis: understanding the role of central pain and current approaches to its treatment. J Rheumatol. 2011:38(8):1546-51.

9. Bjordal JM, Ljunggren AE, Klovning A, Slordal L. NSAIDs, including coxibs, probably do more harm than good, and paracetamol is ineffective for hip OA. Ann Rheum Dis. 2005;64(4):655-6 author reply 656 
10. Fajardo M, Di Cesare PE. Disease-modifying therapies for osteoarthritis: current status. Drugs Aging. 2005;22(2):141-61.

11. Jevsevar DS. Treatment of osteoarthritis of the knee: evidence-based guideline, 2nd edition. J Am Acad Orthop Surg. 2013;21(9):571-6.

12. Abbott JH, Robertson MC, Chapple C, Pinto D, Wright AA. Leon de la Barra S, Baxter GD, Theis JC, Campbell AJ. Manual therapy, exercise therapy, or both, in addition to usual care, for osteoarthritis of the hip or knee: a randomized controlled trial. 1: clinical effectiveness. Osteoarthr Cartil. 2013; 21(4):525-34.

13. Kappetijn $\mathrm{O}$, van Trijffel E, Lucas C. Efficacy of passive extension mobilization in addition to exercise in the osteoarthritic knee: an observational parallelgroup study. Knee. 2014;21(3):703-9.

14. Ali SS, Ahmed SI, Khan M, Soomro RR. Comparing the effects of manual therapy versus electrophysical agents in the management of knee osteoarthritis. Pak J Pharm Sci. 2014;27(4 Suppl):1103-6.

15. Bisset L, Hing W, Vicenzino B. A systematic review of the efficacy of MWM. In: Vicenzino B, Hing W, Rivett D, Hall T, editors. Mobilization with movement: the art and the science. Chatswood: Churchill Livingstone; 2011. p. 26-63.

16. Vicenzino B, Paungmali A, Buratowski S, Wright A. Specific manipulative therapy treatment for chronic lateral epicondylalgia produces uniquely characteristic hypoalgesia. Man Ther. 2001;6(4):205-12.

17. Paungmali A, O'Leary S, Souvlis T, Vicenzino B. Naloxone fails to antagonize initial hypoalgesic effect of a manual therapy treatment for lateral epicondylalgia. J Manip Physiol Ther. 2004;27(3):180-5.

18. Collins $N$, Teys $P$, Vicenzino B. The initial effects of a Mulligan's mobilization with movement technique on dorsiflexion and pain in subacute ankle sprains. Man Ther. 2004;9(2):77-82.

19. Vicenzino $B$, Branjerdporn $M$, Teys $P$, Jordan $K$. Initial changes in posterior talar glide and dorsiflexion of the ankle after mobilization with movement in individuals with recurrent ankle sprain. J Orthop Sports Phys Ther. 2006;36(7):464-71.

20. Delgado-Gil JA, Prado-Robles E, Rodrigues-de-Souza DP, Cleland JA, Fernandez-de-las-Penas C, Alburquerque-Sendin F. Effects of mobilization with movement on pain and range of motion in patients with unilateral shoulder impingement syndrome: a randomized controlled trial. J Manip Physiol Ther. 2015;38(4):245-52

21. Beselga C, Neto F, Alburquerque-Sendin F, Hall T, Oliveira-Campelo N. Immediate effects of hip mobilization with movement in patients with hip osteoarthritis: a randomised controlled trial. Man Ther. 2015.

22. Moss $\mathrm{P}$, Sluka $\mathrm{K}$, Wright $\mathrm{A}$. The initial effects of knee joint mobilization on osteoarthritic hyperalgesia. Man Ther. 2007;12(2):109-18.

23. Takasaki H, Hall T, Jull G. Immediate and short-term effects of Mulligan's mobilization with movement on knee pain and disability associated with knee osteoarthritis: a prospective case series. Physiother Theory Pract. 2013;29(2):87-95.

24. Kaya Mutlu E, Ercin E, Razak Ozdincler A, Ones N. A comparison of two manual physical therapy approaches and electrotherapy modalities for patients with knee osteoarthritis: a randomized three arm clinical trial. Physiother Theory Pract. 2018;34(8):600-12.

25. Altmis H, Oskay D, Elbasan B, Duzgun I, Tuna Z. Mobilization with movement and kinesio taping in knee arthritis-evaluation and outcomes. Int Orthop. 2018:42(12):2807-15.

26. Brim RL, Miller FG. The potential benefit of the placebo effect in shamcontrolled trials: implications for risk-benefit assessments and informed consent. J Med Ethics. 2013:39(11):703-7.

27. Rennie D. CONSORT revised--improving the reporting of randomized trials. JAMA. 2001;285(15):2006-7.

28. Kellgren JH, Lawrence JS. Radiological assessment of osteo-arthrosis. Ann Rheum Dis. 1957:16(4):494-502

29. Altman RD. The classification of osteoarthritis. J Rheumatol Suppl. 1995;43:42-3.

30. Mulligan BR. Manual therapy: NAGS, SNAGS, MWMS etc. 6th ed. Wellington: Plane View Services Ltd; 2010.

31. Vicenzino $B$, Collins $D$, Benson $H$, Wright A. An investigation of the interrelationship between manipulative therapy-induced hypoalgesia and sympathoexcitation. J Manip Physiol Ther. 1998;21(7):448-53.

32. Sindhu BS, Shechtman O, Tuckey L. Validity, reliability, and responsiveness of a digital version of the visual analog scale. J Hand Ther. 2011;24(4):356-64.

33. Hawker GA, Mian S, Kendzerska T, French M. Measures of adult pain: visual analog scale for pain (VAS pain), numeric rating scale for pain (NRS pain), McGill pain questionnaire (MPQ), short-form McGill pain questionnaire (SF$\mathrm{MPQ}$ ), chronic pain grade scale (CPGS), short Form-36 bodily pain scale (SF36 BPS), and measure of intermittent and constant osteoarthritis pain (ICOAP). Arthritis Care Res (Hoboken). 2011;63(Suppl 11):S240-52.
34. Wessel J. The reliability and validity of pain threshold measurements in osteoarthritis of the knee. Scand J Rheumatol. 1995;24(4):238-42.

35. Grafton KV, Foster NE, Wright CC. Test-retest reliability of the short-form McGill pain questionnaire: assessment of intraclass correlation coefficients and limits of agreement in patients with osteoarthritis. Clin J Pain. 2005;21(1):73-82.

36. Mutlu EK, Ozdincler AR. Reliability and responsiveness of algometry for measuring pressure pain threshold in patients with knee osteoarthritis. J Phys Ther Sci. 2015;27(6):1961-5.

37. Vanderweeen $L$, Oostendorp RA, Vaes P, Duquet W. Pressure algometry in manual therapy. Man Ther. 1996;1(5):258-65.

38. Bellamy N, Buchanan WW, Goldsmith CH, Campbell J, Stitt LW. Validation study of WOMAC: a health status instrument for measuring clinically important patient relevant outcomes to antirheumatic drug therapy in patients with osteoarthritis of the hip or knee. J Rheumatol. 1988;15(12):1833-40.

39. Angst F, Aeschlimann A, Steiner W, Stucki G. Responsiveness of the WOMAC osteoarthritis index as compared with the SF-36 in patients with osteoarthritis of the legs undergoing a comprehensive rehabilitation intervention. Ann Rheum Dis. 2001;60(9):834-40.

40. Parent $\mathrm{E}$, Moffet $\mathrm{H}$. Comparative responsiveness of locomotor tests and questionnaires used to follow early recovery after total knee arthroplasty. Arch Phys Med Rehabil. 2002;83(1):70-80.

41. Podsiadlo D, Richardson S. The timed "up \& go": a test of basic functional mobility for frail elderly persons. J Am Geriatr Soc. 1991;39(2):142-8.

42. Alghadir A, Anwer S, Brismée J-M. The reliability and minimal detectable change of Timed Up and Go test in individuals with grade 1-3 knee osteoarthritis. BMC Musculoskelet Disord. 2015;16(1):174.

43. Mentiplay BF, Perraton LG, Bower KJ, Adair B, Pua YH, Williams GP, McGaw R, Clark RA. Assessment of lower limb muscle strength and power using hand-held and fixed dynamometry: a reliability and validity study. PLoS One. 2015;10(10):e0140822

44. Maffiuletti NA, Bizzini M, Desbrosses K, Babault N, Munzinger U. Reliability of knee extension and flexion measurements using the con-Trex isokinetic dynamometer. Clin Physiol Funct Imaging. 2007;27(6):346-53.

45. van Trijffel E, van de Pol RJ, Oostendorp RA, Lucas C. Inter-rater reliability for measurement of passive physiological movements in lower extremity joints is generally low: a systematic review. J Physiother. 2010;56(4):223-35.

46. Davis S. Mixed Models for Repeated Measures using Categorical time Effects (MMRM). In, editors. Chichester, UK: Wiley; 2014. p. 130-184.

47. Kenward MG, White IR, Carpenter JR. Should baseline be a covariate or dependent variable in analyses of change from baseline in clinical trials? By G. F. Liu, K. Lu, R. Mogg, M. Mallick and D. V. Mehrotra, statistics in medicine 2009; 28:2509-2530. Stat Med. 2010;29(13):1455-6 author reply 1457.

48. Eberle E, Ottillinger B. Clinically relevant change and clinically relevant difference in knee osteoarthritis. Osteoarthr Cartil. 1999;7(5):502-3.

49. O'Brien T, Vicenzino B. A study of the effects of Mulligan's mobilization with movement treatment of lateral ankle pain using a case study design. Man Ther. 1998;3(2):78-84.

50. Backstrom KM. Mobilization with movement as an adjunct intervention in a patient with complicated de Quervain's tenosynovitis: a case report. J Orthop Sports Phys Ther. 2002;32(3):86-94 discussion 94-87.

51. Paungmali A, Vicenzino B, Smith M. Hypoalgesia induced by elbow manipulation in lateral epicondylalgia does not exhibit tolerance. J Pain. 2003:4(8):448-54.

52. Sterling $M$, Jull $G$, Wright A. Cervical mobilisation: concurrent effects on pain, sympathetic nervous system activity and motor activity. Man Ther. 2001;6(2):72-81.

53. Paungmali A, O'Leary S, Souvlis T, Vicenzino B. Hypoalgesic and sympathoexcitatory effects of mobilization with movement for lateral epicondylalgia. Phys Ther. 2003;83(4):374-83.

54. Vicenzino B, Collins D, Wright $A$. The initial effects of a cervical spine manipulative physiotherapy treatment on the pain and dysfunction of lateral epicondylalgia. Pain. 1996;68(1):69-74.

55. Skyba DA, Radhakrishnan R, Rohlwing JJ, Wright A, Sluka KA. Joint manipulation reduces hyperalgesia by activation of monoamine receptors but not opioid or GABA receptors in the spinal cord. Pain. 2003;106(1-2):159-68.

56. Hurley MV, Newham DJ. The influence of arthrogenous muscle inhibition on quadriceps rehabilitation of patients with early, unilateral osteoarthritic knees. Br J Rheumatol. 1993;32(2):127-31. 
57. Deyle GD, Henderson NE, Matekel RL, Ryder MG, Garber MB, Allison SC. Effectiveness of manual physical therapy and exercise in osteoarthritis of the knee. A randomized, controlled trial. Ann Intern Med. 2000;132(3):173-81.

58. Deyle GD, Allison SC, Matekel RL, Ryder MG, Stang JM, Gohdes DD, Hutton $J P$, Henderson NE, Garber MB. Physical therapy treatment effectiveness for osteoarthritis of the knee: a randomized comparison of supervised clinical exercise and manual therapy procedures versus a home exercise program. Phys Ther. 2005;85(12):1301-17.

\section{Publisher's Note}

Springer Nature remains neutral with regard to jurisdictional claims in published maps and institutional affiliations.

Ready to submit your research? Choose BMC and benefit from:

- fast, convenient online submission

- thorough peer review by experienced researchers in your field

- rapid publication on acceptance

- support for research data, including large and complex data types

- gold Open Access which fosters wider collaboration and increased citations

- maximum visibility for your research: over $100 \mathrm{M}$ website views per year

At $B M C$, research is always in progress.

Learn more biomedcentral.com/submissions 